\title{
Descriptions of new species with a key to identification of the genus Neodexiopsis Malloch (Diptera, Muscidae) in Brazil
}

\author{
Nise do Carmo Costacurta ${ }^{1}$, Márcia Souto Couri² \& Claudio José Barros de Carvalho ${ }^{3}$
}

1'Hospital de Clínicas, Univ. Federal do Paraná, 80060-240 Curitiba-Paraná, Brazil.
${ }^{2}$ Museu Nacional, Quinta da Boa Vista, São Cristóvão, 20940-040 Rio de Janeiro-RJ, Brazil. mcouri@attglobal.net
${ }^{3}$ Departamento de Zoologia, Univ. Federal do Paraná, Caixa Postal 19020, 81531-980 Curitiba-PR, Brazil. cjbcarva@ufpr.br

\begin{abstract}
Descriptions of new species with a key to identification of the genus Neodexiopsis Malloch (Diptera, Muscidae) in Brazil. Nine new species of Neodexiopsis Malloch from Paraná, southern Brazil, are described: Neodexiopsis cinerea sp. nov. and $N$. paranaensis sp. nov. from Ponta Grossa; $N$. facilis sp. nov., N. legitima sp. nov., $N$. similis sp. nov. and $N$. uber sp. nov. from Guarapuava; N. erecta sp. nov., N. pura sp. nov. and N. rara sp. nov. from Colombo. A key to the identification of the Brazilian species of Neodexiopsis is also presented.
\end{abstract}

KEYWORDS. Coenosiinae, Coenosiini, Taxonomy.

RESUMO. Descrição de novas espécies e chave de identificação do gênero Neodexiopsis Malloch (Diptera, Muscidae) no Brasil. Nove espécies novas de Neodexiopsis Malloch do Paraná, sul do Brasil, são descritas: Neodexiopsis cinerea sp. nov. e $N$. paranaensis sp. nov. de Ponta Grossa; $N$. facilis sp. nov., $N$. legitima sp. nov., $N$. similis sp. nov. e $N$. uber sp. nov. de Guarapuava; $N$. erecta sp. nov., $N$. pura sp. nov. e $N$. rara sp. nov. de Colombo. É incluída também uma chave de identificação das espécies brasileiras de Neodexiopsis.

PALAVRAS-CHAVE. Coenosiinae, Coenosiini, Taxonomia.

Neodexiopsis Malloch, 1920 is one of the most speciose genera found in the Neotropical Coenosiini (Snyder 1957b; Couri \& Carvalho 2002; Carvalho et al. 2005). Most of the species have light brown to dark brown bodies and yellow to brown legs (Malloch 1920; Couri \& Albuquerque 1979). Adults are small to medium sized predatory flies that inhabitant forests or open habitats.

Neodexiopsis is probably a monophyletic group (Carvalho 1989b) but no synapomorphic characters were found in a cladistic analysis of Coenosiini (Couri \& Pont 2000). Neodexiopsis was included in the key to the world genera of Coenosiini (Couri \& Pont 1999). Puerto Rican species have been described and keyed (Snyder 1957a; Couri \& Carvalho 2002) and species of Neodexiopsis have been keyed to the ovata group (Snyder 1958). Currently, approximately 29 species of Neodexiopsis occur in Brazil (Couri \& Carvalho 2002).

From a survey of natural areas with Malaise traps in Paraná, southern Brazil (see Costacurta et al. 2003), we found several new species of Neodexiopsis. Here we describe nine new species of Neodexiopsis and present a key to identification for the Brazilian species in that genus.

\section{MATERIAL AND METHODS}

Specimens from the Department of Zoology of Universidade Federal do Paraná (DZUP) and the Museu Nacional, Department of Entomology, Rio de Janeiro, Brazil (MNRJ) were studied. The terminology used are in McAlpine (1981) slightly modified by Carvalho (1989a).

All species recorded in Brazil, including nine new species described here, are keyed, except for $N$. brasiliensis (Walker, 1853), since the available data did not permit keying of this species.

Key to Brazilian species

1. Male with anal angle of the wing forming a prominent lobe (Carvalho \& Couri 2002: figs. 126-134); female with anal angle truncated 2

Both sexes with rounded anal angle ................................... 7

2. Palpus yellow with the basal half darker; antenna brown with apex of pedicel and base of flagellomere yellow; sternite 5 with a row of long setae, forming a tuft (Couri \& Carvalho 2002: fig. 121) [Brazil] N. barbiventris Couri \& Albuquerque

Not as above 3

3. Palpus yellow 4

Palpus brown 6

4. Legs yellow with the apical third of fore, mid and hind femora brown. Male: antenna with pedicel brown and flagellum brown on basal third and yellow on apical two thirds. Female: antenna entirely yellow [Costa Rica, Panama, Venezuela, Brazil] .............. N. emmesa Malloch

Legs entirely yellow; antenna different from above ....... 5

5. Dorsocentrals $1+2$; costal vein on ventral surface with a long seta at base [Brazil] . . N. cambuquirensis Albuquerque 
Dorsocentrals 1+3; costal vein on ventral surface with no seta at base [Brazil] . N. cera Snyder

6. Antenna brown with apex of pedicel shiny in certain lights; mid femur entirely yellow; fore femur on anterior surface without any long seta at base; fore tibia with a long posterior seta [Brazil, Argentina]

N. neoaustralis Snyder

Antenna dark brown with apex of pedicel and base of flagellomere yellow; mid femur with the apical third brown; fore femur on anterior surface with a strong seta at base; fore tibia with a submedian anterior seta [Brazil] N. parvula Albuquerque

7. Both basal and apical pairs of scutellar setae weak [Brazil, Uruguay] N. rufipes (Macquart)

At least the basal scutellar pair of setae long.... ... 8

8. Apical pair of scutellar setae about half as long as basal pair..... 9

Apical pair of scutellar setae as long as basal pair ....... 16

9. Antenna light brown with apex of pedicel and base of flagellum yellow; mid femur with 2 anterior setae; hind tibia with one median seta on anterodorsal and posterodorsal surfaces, one short sub-median anteroventral seta, one anterodorsal and one dorsal pre-apical [Brazil] N. facilis sp. nov.

Not as above 10

10. Fore tibia with short ventral and posteroventral setae apically (Couri \& Carvalho 2002: fig. 122); abdomen with a brown median vitta and without lateral marks [Brazil] .................... N. pectinata Couri \& Albuquerque

Fore tibia without short ventral and posteroventral setae apically; abdomen with brown lateral round marks and with a brown median vitta .. 11

11. Thorax with a median brown vitta; mid femur on anterior surface with one seta or bare; hind tibia with one anterior to anterodorsal seta and no setae on anteroventral surface

Thorax with more than one brown vitta; mid femur on anterior surface with 1-4 setae; hind tibia with 2 anterodorsal and one anteroventral setae .. 14

12. Thorax with a median brown vitta; hind tibia with two anterodorsal setae and one median dorsal setae; legs yellow with apical $1 / 4$ of hind femur brown, tarsi brown [Brazil]... $N$. similis $\mathbf{s p . ~ n o v . ~}$

Not as above 13

13. Proboscis yellow; mid femur entirely yellow; fore femur with a row of anterodorsal setae; fore and mid femora and tibiae with short and fine ventral cilia [Peru, Brazil; North America] N. calopyga (Loew)
Proboscis brown; mid and hind femora yellow with brown apices; fore femur with an anteroventral and anterodorsal row of setae; fore and mid femora and tibiae without short and fine ventral cilia [Brazil]

N. subtilis Couri \& Albuquerque

14. Antenna dark brown, with apex of pedicel lighter; fore femur with complete rows of anterodorsal and anteroventral setae [Brazil, Argentina]

Not as above N. setipuncta Snyder 15

15. General colour yellow; antenna yellow; fore femur entirely yellow and with a complete row of anterodorsal setae; mid tibia with a median anterior seta [Brazil] N. elegans Couri \& Albuquerque

General colour grey; antenna grey with apex of pedicel lighter; fore femur mostly yellow, brown on apical dorsal half; mid tibia with a submedian anterior seta [Brazil] ... . N. vulgaris Couri \& Albuquerque

16. Hind tibia without a median or submedian anteroventral seta 17

Hind tibia with a median or submedian anteroventral seta

17. Mid femur with two or three anterior setae; mesonotum with five brown vittae, the median one reaching apex of scutellum 18

Mid femur with one median or submedian anterior seta; mesonotum with vittae not as below

21

18. Mid femur with three anterior setae; hind tibia with an anterodorsal median and a posterodorsal median and one dorsal pre-apical setae [Brazil]

$N$. paranaensis $\mathbf{s p . ~ n o v . ~}$

Not as above 19

19. Antenna brown, with apex of pedicel and base of flagellum yellow; palpus yellow; hind tibia on anterior to anterodorsal surface without long and fine cilia [Brazil] $N$. erecta $\mathbf{s p . ~ n o v . ~}$ Antenna and palpus black; hind tibia not as above .... 20

20. Hind tibia on anterior to anterodorsal surface with long and fine cilia [Brazil] ................ N. rustica Albuquerque

Hind tibia on anterior to anterodorsal surface with only a median seta [Brazil] N. sulina Couri

21. Tergite 5 with apex fulvous and in sharp contrast to the remaining dark abdominal tergites [Brazil]

N. croceafrons Snyder

Tergite 5 concoloured with the other abdominal tergites ..

22. Head and thorax grey pruinose; legs yellow with the dorsal 
surface of fore femur, apex of mid femur and apical third of hind femur brown; mid femur with a short median anterior seta [Brazil] ........... N. flavipalpis Albuquerque

Head and thorax golden pruinose; legs dark brown with trochanter and femora-tibial junctions yellow; mid femur with a long median anterior seta 25

23. Mesonotum with three brown vittae, the median one reaching scutellum [Brazil]

N. fulvifrontis Couri \& Albuquerque

Mesonotum with the median vitta not continued onto scutellum .....

24

24. Flagellomere with pointed apex; last abdominal segment yellow [Brazil] .................... paulistensis Albuquerque

Flagellomere with round apex; last abdominal segment concolour with others tergites [Panama, ?Jamaica, Ecuador, Peru, Brazil, Paraguay, Argentina; North America] .. N. rufitibia (Stein)

25. General colour dark brown; antenna, palpus and legs dark brown; halter with knob black; calypteres brown in male and yellow with brown margins and fringe in female; abdomen without brown spots [Chile, Brazil, Argentina] N. nigerrima (Malloch)

General colour grey, sometimes with yellow pruinescence; antenna, palpus and legs with another colour; halter with knob yellow to light brown; calypteres yellowishwhite; abdomen frequently with a pair of brown round lateral spots 26

26. Mesonotum without dorsal vittae 27 Mesonotum with dorsal vittae 28

27. Costal spine absent 29

Costal spine present 30

28. Legs yellowish with the a anterior surface of fore femur brown; palpus brown; epistoma not prominent; pretarsus without a basal ventral seta [Brazil] N. albisquama (Albuquerque)

Legs entirely yellow; palpus yellow on basal two-thirds and brown on apical third; epistoma prominent; pretarsus with a basal ventral seta [Brazil] N. plumbifrons (Albuquerque)

29. Legs and halter orange; abdomen without lateral brown spots [Brazil] N. itatiaiensis Albuquerque

Fore leg brown, mid and hind legs yellow, brown on apical half; tarsi brown; halter yellow; abdomen with brown lateral marks and one long median stripe [Brazil] ..........

N. pura sp. nov.

30. Antenna black with apex of pedicel lighter 31 Antenna entirely dark brown or with another colour .... 33
31. Mesonotum with the dorsal vittae coincident with the dorsocentral rows of setae reaching the insertion of the basal pair of scutellar setae [Brazil]

N. alacris Couri \& Albuquerque

Mesonotum with the dorsal vittae coincident with the dorsocentral rows of setae and not reaching insertion of the basal pair of scutellar setae. 32

32. Palpus entirely brown, or brown on basal third; legs yellow, except fore femur and apexes of mid and hind femora brown [Brazil] N. mesofulvata (Albuquerque)

Palpus dark brown; legs dark brown, except apexes of femora and bases of tibiae yellow [Brazil, Argentina] ... N. cirratipila Snyder

33. Mesonotum with five brown dorsal vittae 34 Mesonotum with 2-4 brown dorsal vittae 37

34. Legs yellow with apexes of mid and hind femora brown; tarsi light brown [Brazil] ....

Legs not coloured as above N. ponti Couri

35. Legs black with yellow tibiae; mid femur with a median seta on anterior, posteroventral surface with 2 long and sparse setae on basal third [Brazil]

................................... N. latimaculata (Albuquerque)

Not as above 36

36. Legs yellow, anterior surface of fore femur sligthly brown; mid femur with 2 very distinctive setae on anterior surface; posteroventral surface with 4 long and sparse setae [Brazil] N. rara sp. nov.

Legs brown, base of all femora and femora-tibial articulations reddish yellow; mid femur with 2-3 anterior setae; posteroventral surface with three setae [Brazil] N. legitima sp. nov.

37. Antenna black with apexes of pedicel and flagellum yellow; palpus brown; legs yellow with dorsal surface of fore femur and apex of hind femur brown; hind tibia with an anteroventral, anterodorsal and posterodorsal submedian setae, dorsal and anterodorsal surfaces with an apical setae [Brazil]

Not as above

N. xanthopoda Albuquerque

38. Antenna dark brown with apex of pedicel shiny; palpus brown; mesonotum with four brown vittae dorsal vittae [Brazil] ....................... N. novissima Couri \& Albuquerque

Antenna, palpus and mesonotum not above ................ 39

39. Mesonotum with two brown dorsal vittae [Brazil] ......... N. tinctifacies (Albuquerque)

Mesonotum with three brown dorsal vittae 40

40. Palpus dark brown; femora brown, grey pollinose with 
yellow apex [Brazil] .............................. cinerea $\mathbf{s p . ~ n o v . ~}$

Palpus yellow; femora mostly yellow ... 41

41. Antenna blackish brown; femora yellow [Brazil] ............ N. antennata Couri

Antenna blackish brown with apex of pedicel and basal third of flagellum yellow; dorsal surface of fore femur and apical $1 / 4$ of mid femur brown [Brazil] .

N. uber sp. nov.

Descriptions

\section{Neodexiopsis cinerea $\mathbf{s p . ~ n o v . ~}$}

(Figs. 1-6)

Diagnosis.-Antenna dark brown, with apex of pedicel grey pollinose. Ocellar seta long. Height of gena about 0.20 of eye height (Fig. 1). Mesonotum brown, golden pollinose and with 3 fine and well marked brown vittae at acrostichal and dorsocentral surfaces (Fig. 2). Apical scutellar seta long, as long as the basal one. Coxae and femora brown with grey pollinosity, apex of femora and all tibiae yellow; tarsi dark brown. Hind tibia with a median seta on anteroventral surface.

Female.-Length: body: 2.8-3.2 mm; wing: 3.2-3.7 mm.

Colour: Parafacial, fronto-orbital plate and area around ocellar triangle golden polinose. Face and frons brown. Antenna dark brown, with apex of pedicel grey pollinose. Arista and palpus dark brown. Calypter whitish and halter yellow. Wing hyaline. Mesonotum brown golden pollinose and with 3 fine and well marked brown vittae at acrostichal and dorsocentral surfaces (Fig. 2). Pleurae brown with grey pollinosity. Coxae and femora brown with grey pollinosity, apex of femora and all tibiae yellow; tarsi dark brown. Abdomen brown with grey pollinosity; tergites with brown lateral clouds and one median stripe (Fig. 3).

Head: Eyes bare; at level of anterior ocellus separated by about 0.40 of head width. Inner and outer vertical setae medium, the upper one outwards directed. Frontal row with 4 pairs of long setae, the upper one backwards directed. Ocellar setae long and forwards directed. Antenna with flagellum 2.0-2.2 times as long as pedicel. Arista shortly pubescent. Height of the gena about 0.20 of eye height (Fig. 1).

Thorax: acrostichal hairs distinct, in 2 rows, the last pair longer. Presuturals 1; supra-alar 1; post supra-alar 1. Scutellum with two long pairs of setae, a basal and an apical one. Anepimeron with 4 long setae. Fore femur with complete rows of anterodorsal and anteroventral setae. Tibia on posterior surface with a long median seta; dorsal, posterodorsal and posterior surfaces with an apical seta. Mid femur with 2-3 anterior setae inserted on middle third; posterior surface with 2 pre-apical setae. Mid tibia with a sub-median anterior and a median posterior setae; ventral, anteroventral and posteroventral surfaces with an apical strong seta. Hind femur with complete rows of anterodorsal and anteroventral setae; ventral surface with fine and long setae on basal half. Hind tibia with a median anterodorsal and posterodorsal setae, one short sub-median anteroventral and one dorsal pre-apical; anterodorsal, anteroventral and ventral surfaces with an apical seta.

Abdomen: tergite 3 with one pair of lateral setae; tergites 4-5 with 2 pairs of lateral setae (Fig. 3).

Ovipositor: Figs. 4-5. Spermatheca: Fig. 6.

Geographical distribution: Brazil (Paraná).

Comments. This species can be identified by characters in the key. Male is unknown.

Holotype female. BRAZIL: Paraná, Ponta Grossa, Vila Velha, Reserva IAPAR, BR. 376 [road], 10.XI.1986, Lev. [survey] Ent. [entomological] PROFAUPAR [entomological project of Paraná State], Malaise [trap] (DZUP).

Paratypes.-16 females (DZUP, MNRJ): BRAZIL: Paraná, Ponta Grossa, Vila Velha, Reserva IAPAR, BR. 376, 15.IX.1986 (1), Lev. Ent. PROFAUPAR, Malaise; ibidem, 22.IX.1986 (1); ibidem, 06.X.1986 (1); ibidem, 13.X.1986 (1); ibidem, 20.X.1986 (2); ibidem, 03.XI.1986 (2); ibidem, 10.XI.1986 (1); ibidem, 17.XI.1986 (1); ibidem, 01.XII.1986 (1); ibidem, 08.XII.1986 (1); ibidem,18.V.1987 (1); ibidem, 20.VII.1986 (2). Guarapuava, Estância Águas de Santa Clara, 03.XI.1986 (1), Lev. Ent. PROFAUPAR, Malaise.

\section{Neodexiopsis erecta $\mathbf{s p . ~ n o v . ~}$}

(Figs. 7-12)

Diagnosis.-Antenna brown, with apex of pedicel and base of flagellum yellow. Ocelar seta short. Height of gena, 0.10 0.14 of eye height (Fig. 7). Mesonotum brown with grey pollinosity and with 5 brown vittae at acrostichal, dorsocentral and intralar surfaces (Fig. 8). Both pairs of scutellar setae long, but the apical one about $80 \%$ of the basal one. Legs yellow, with apical third of mid and hind femora and all mid and hind tibiae brown. Hind tibia with no setae on anteroventral surface.

Female.-Length: body: $3.5 \mathrm{~mm}$; wing: $3.9-4.8 \mathrm{~mm}$.

Colour: General body colour brown with grey pollinosity; antenna brown, with apex of pedicel and base of flagellum yellow; arista brown. Palpus yellow. Frons brown. Frontoorbital plate, parafacial and gena brown with grey pollinosity. Mesonotum brown with grey pollinosity and with 5 brown vittae at acrostichal, dorsocentral and intra-alar surfaces (Fig. 8). Pleurae with grey pollinosity. Legs yellow, with apical third of mid and hind femora and all mid and hind tibiae brown. Abdomen with lateral and median brown marks (Fig. 9). Tergite 1 yellow at base (some specimens with base of tergites 2 and 3 yellow).

Head: eyes bare; at level of anterior ocellus separated by $0.38-0.40$ of head width. Inner and outer vertical setae medium, the latter one outwards directed. Frontal row with 3 pairs of long setae, the upper one backwards directed. Ocellar setae short. Antenna with flagellum 2,3-2,5 times as long as pedicel. Arista shortly pubescent. Height of gena about $0.10-0.14$ of eye height (Fig. 7).

Thorax: acrostichal hairs distinct, in 2 rows, the last pair longer. Presuturals 1; supra-alar 1; post supra-alar 1. Scutellum with two long pairs of setae, a basal and an apical one; the apical one about $80 \%$ of the length of the basal one. Anepimeron with 4 long setae. Fore femur with complete rows of anterodorsal and anteroventral setae, the last row longer. 

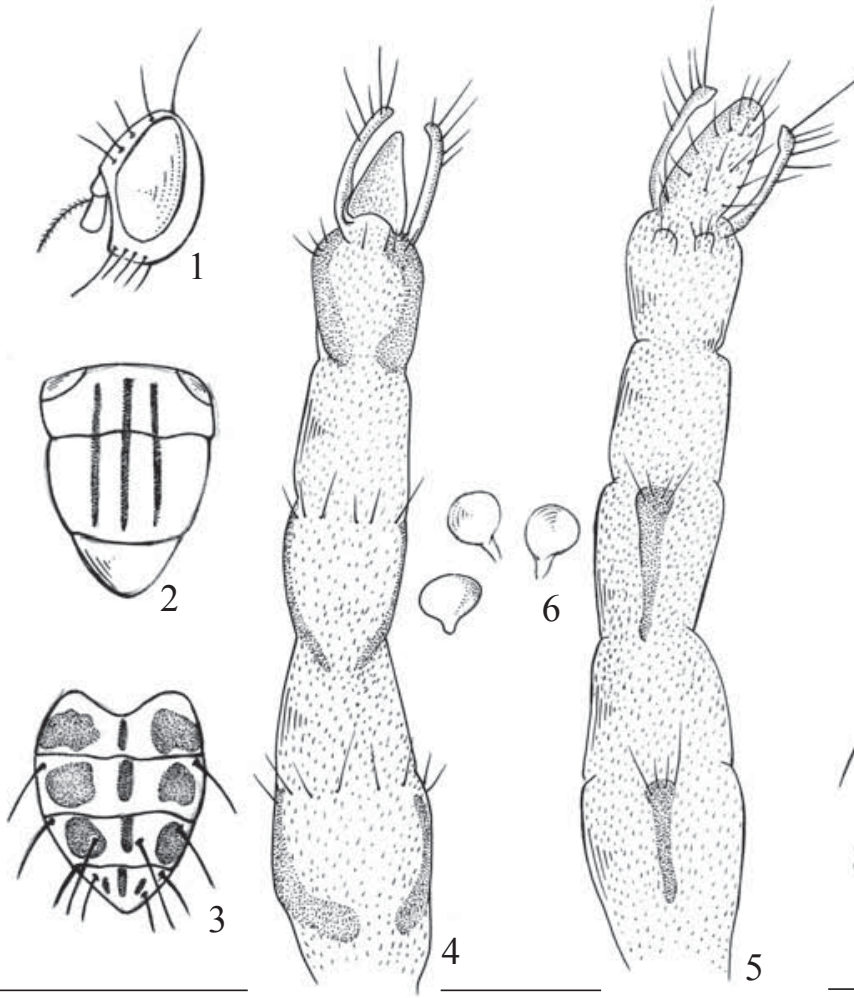
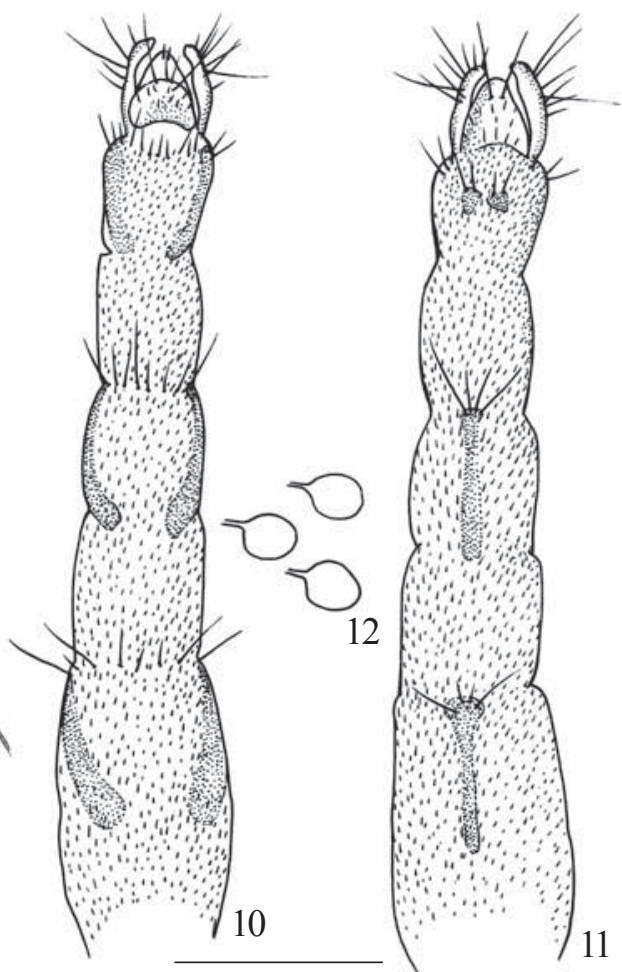

Figs. 1-12. 1-6, Neodexiopsis cinerea sp. nov., female: 1, Head, lateral view; 2, Mesonotum, dorsal view; 3, Abdomen, dorsal view; 4, Ovipositor, dorsal view; 5, Ovipositor, ventral view; 6, Spermathecae. Scale bar, figs. 1-3 = 2 mm; figs. 4-6 = 0,5 mm. 7-12, Neodexiopsis erecta sp. nov., female: 7, Head, lateral view; 8, Mesonotum, dorsal view; 9, Abdomen, dorsal view; 10, Ovipositor, dorsal view; 11, Ovipositor, ventral view; 12, Spermathecae. Scale bar, figs. $7-9=2 \mathrm{~mm}$; figs. $10-11=0,5 \mathrm{~mm}$.

Tibia on posterior surface with a long median seta; dorsal, and posterior surfaces with pre-apical setae; posterodorsal and posterior surfaces with an apical seta. Mid femur with 2 anterior setae inserted on middle third, one short and one long; posteroventral surface with long and sparse setae; posterior surface with 2 pre-apical setae. Mid tibia with a submedian anterodorsal seta; a posterior submedian seta and one strong ventral. Hind femur with complete rows of anterodorsal and anteroventral setae, longer on apical third. Hind tibia with an anterodorsal and one posterodorsal median setae; apical setae on dorsal and ventral surfaces, the last one stronger.

Abdomen: Tergite 3 with one lateral pair of setae. Tergites 4 and 5 with a discal row of setae (Fig. 9).

Ovipositor: Figs. 10, 11. Spermatheca: Fig. 12.

Geographical distribution: Brazil (Paraná).

Comments. This species can be identified by characters in the key. Male is unknown.

Holotype female. BRAZIL: Paraná, Colombo, EMBRAPA, BR. 476 [road], Km. 20, 26/I/1987 (1), Lev. [survey] Ent. [entomological] PROFAUPAR [entomological project of Paraná State], Malaise [trap] (DZUP).

Paratypes.-15 females (DZUP, MNRJ): BRAZIL: Paraná, Colombo, EMBRAPA, BR. 476, Km. 20, 09.III.1987 (1), Lev. Ent. PROFAUPAR, Malaise; ibidem, 08.VI.1987 (1); ibidem, 29.VI.1987 (1); ibidem, 06.VII.1987 (1). Ponta Grossa, Vila Velha, Reserva IAPAR, BR 376, 27.X.1986 (1), Lev. Ent. PROFAUPAR, Malaise; ibidem,
08.XII.1986 (1); ibidem, 11.V.1987 (1); ibidem, 18.V.1987 (1); ibidem, 27.IV.1987 (1); ibidem, 01.VI.1987 (1). Guarapuava, Estância Águas Sta. Clara, 15.IX.1986 (1), Lev. Ent. PROFAUPAR, Malaise; ibidem, 13.X.1986 (1); ibidem, 03.XI.1986 (1); ibidem, 10.XI.1986 (1); ibidem, 16.II.1987 (1).

\section{Neodexiopsis facilis sp. nov.}

(Figs. 13-22)

Diagnosis.-Antenna brown, with apex of pedicel and base of flagellum yellow. Ocelar seta long. Height of gena 0.19-0.21 of eye height (Fig. 13). Mesonotum with only very faint brown vittae in some specimens, more visible before suture (Fig. 14). Scutellum with a long basal and a short apical pair of setae. Legs yellow; extreme apex of mid and hind femora brown. Hind tibia with a short median anteroventral seta. Fore femur with about 4-5 strong dorsal setae on middle third.

Male.-Length: body: 3.1-3.6 mm; wing: 3.1-3.8 mm.

Colour: parafacial, fronto-orbital plate and area around ocellar triangle yellow dusted. Face and frons brown. Antenna brown, with apex of pedicel and base of flagellum yellow. Arista brown. Palpus yellow. Calypter whitish and halter yellow. Wing hyaline. Mesonotum brown with grey pollinosity and with a very faint brown vittae visible in some specimens, more visible before suture (Fig. 14). Pleurae brown with grey pollinosity. Legs yellow; extreme apex of mid and hind femora brown. 

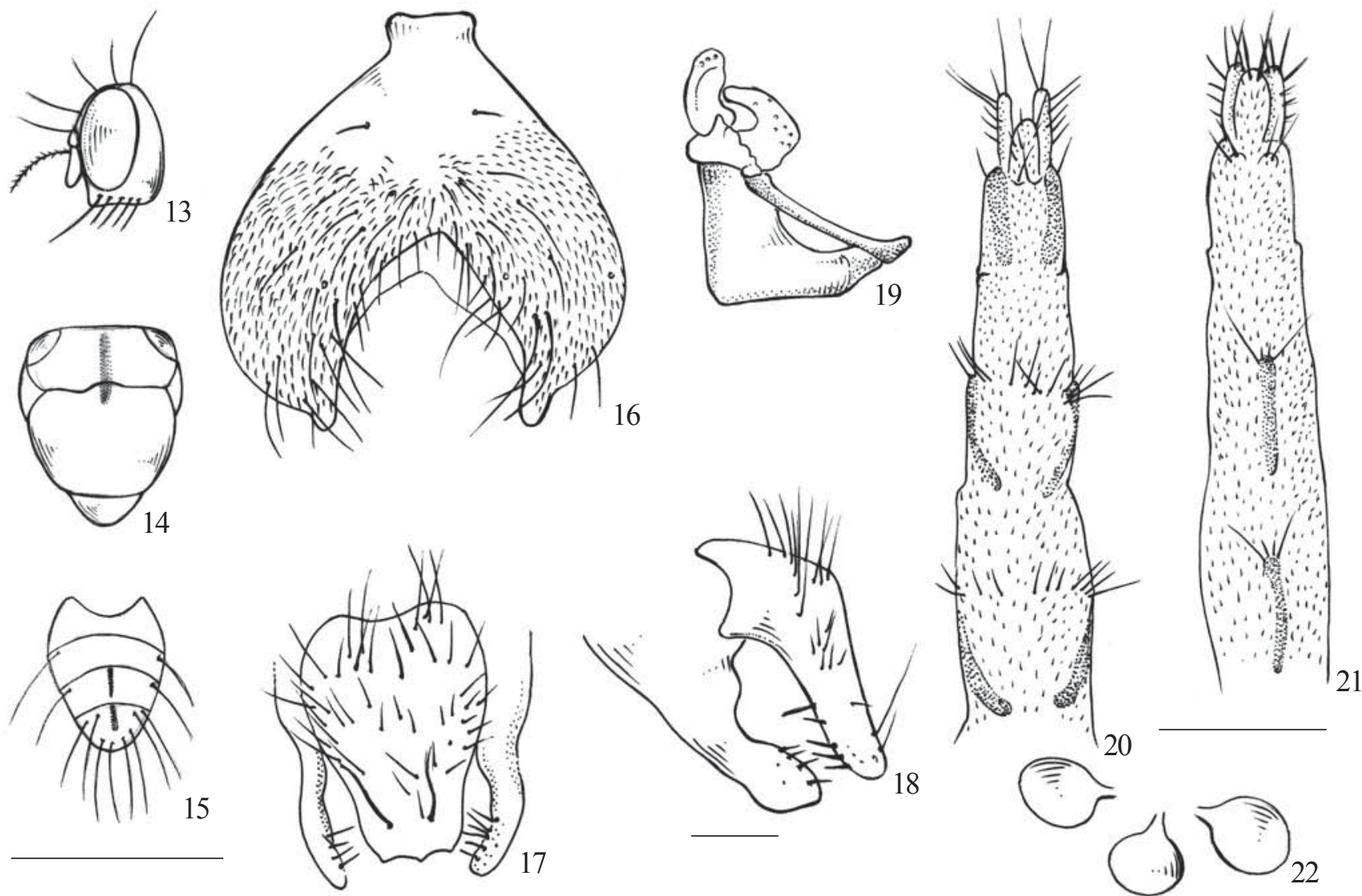

Figs. 13-19. Neodexiopsis facilis sp. nov., male: 13, Head, lateral view; 14, Mesonotum, dorsal view; 15, Abdomen, dorsal view; 16, Sternite 5, dorsal view; 17, Cercal plate and surstyli, dorsal view; 18, Cercal plate and surstyli, lateral view; 19, Phallic complex, lateral view. Figs. 20-22, $N$. facilis sp. nov., female: 20, Ovipositor, dorsal view; 21, Ovipositor, ventral view; 22, Spermathecae. Scale bar, figs. 13-15 = 2 mm; figs. 16-19 $=0,1 \mathrm{~mm}$; figs. $20-22=0,5 \mathrm{~mm}$.

Abdomen brown; with yellow dusted and a very faint median brown stripe, more visible on tergites 4 and 5 (Fig. 15).

Head: eyes bare; at level of anterior ocellus separated by $0.35-0.39$ of head width. Inner and outer vertical setae medium, the latter one outwards directed. Frontal row with 3 pairs of long setae, the upper one backwards directed. Ocellar setae long and forwards directed. Antenna with flagellum 3.3 times as long as pedicel. Arista with short plumae. Height of the gena about $0.19-0.21$ of eye height (Fig. 13).

Thorax: acrostichal hairs distinct, in 1 row. Presuturals 1; supra-alar 1; post supra-alar 1; intra-alars 2. Scutellum with a long basal and a short apical pair of setae. Anepimeron with 4 long setae. Fore femur with complete rows of anterodorsal and anteroventral setae; dorsal surface with 4-5 strong setae on middle third. Tibia on posterior surface with a long median seta; one dorsal on apical third; one posterodorsal pre-apical and one ventral strong apical. Mid femur with a row of sparse anterior setae on basal half; ventral surface with 3 sparse setae on basal third; posterior surface with 2 pre-apical setae. Mid tibia with a sub-median anterior seta and a posterior median seta; ventral, anterodorsal and posterodorsal surfaces with an apical strong seta. Hind femur with complete rows of anterodorsal and anteroventral setae. Hind tibia with an anterodorsal and a posterodorsal median setae, one short submedian anteroventral and one anterodorsal pre-apical; anterodorsal, ventral and posterodorsal surfaces with an apical seta.

Abdomen: tergites 3-4 with lateral setae; tergite 5 with a row of about 4 discal and 4 apical setae (Fig. 15).

Terminalia: Sternite 5 (Fig. 16). cercal plate and surstyli (Figs. 17, 18); aedeagus (Fig. 19).

Female. Similar to male.

Ovipositor: Figs. 20, 21. Spermatheca: Fig. 22.

Geographical distribution: Brazil (Paraná).

Comments: This species can be easily identified by chaetotaxy of hind leg.

Holotype male. BRAZIL: Paraná, Guarapuava, Est. [resort] Águas Sta. Clara, 01.IX.1986, Lev. [survey] Ent. [entomological] PROFAUPAR [entomological project of Paraná State], Malaise [trap] (DZUP).

Paratypes.-26 males and 87 females (DZUP, MNRJ): BRAZIL: Paraná, Colombo, EMBRAPA, BR. 476, Km. 20, 01.IX.1986, 1 female. Lev. Ent. PROFAUPAR, Malaise; ibidem, 27.X.1986, 1 female; ibidem, 03.XI.1986, 1 female; ibidem, 17.XI.1986, 1 female; ibidem, 24.XI.1986, 2 females; ibidem, 02.II.1987, 1 female; ibidem, 09.II.1987, 2 females. Ponta Grossa, Vila Velha, Reserva IAPAR, BR 376, 04.VIII.1986, 1 male and 1 female, Lev. Ent. PROFAUPAR, Malaise; 

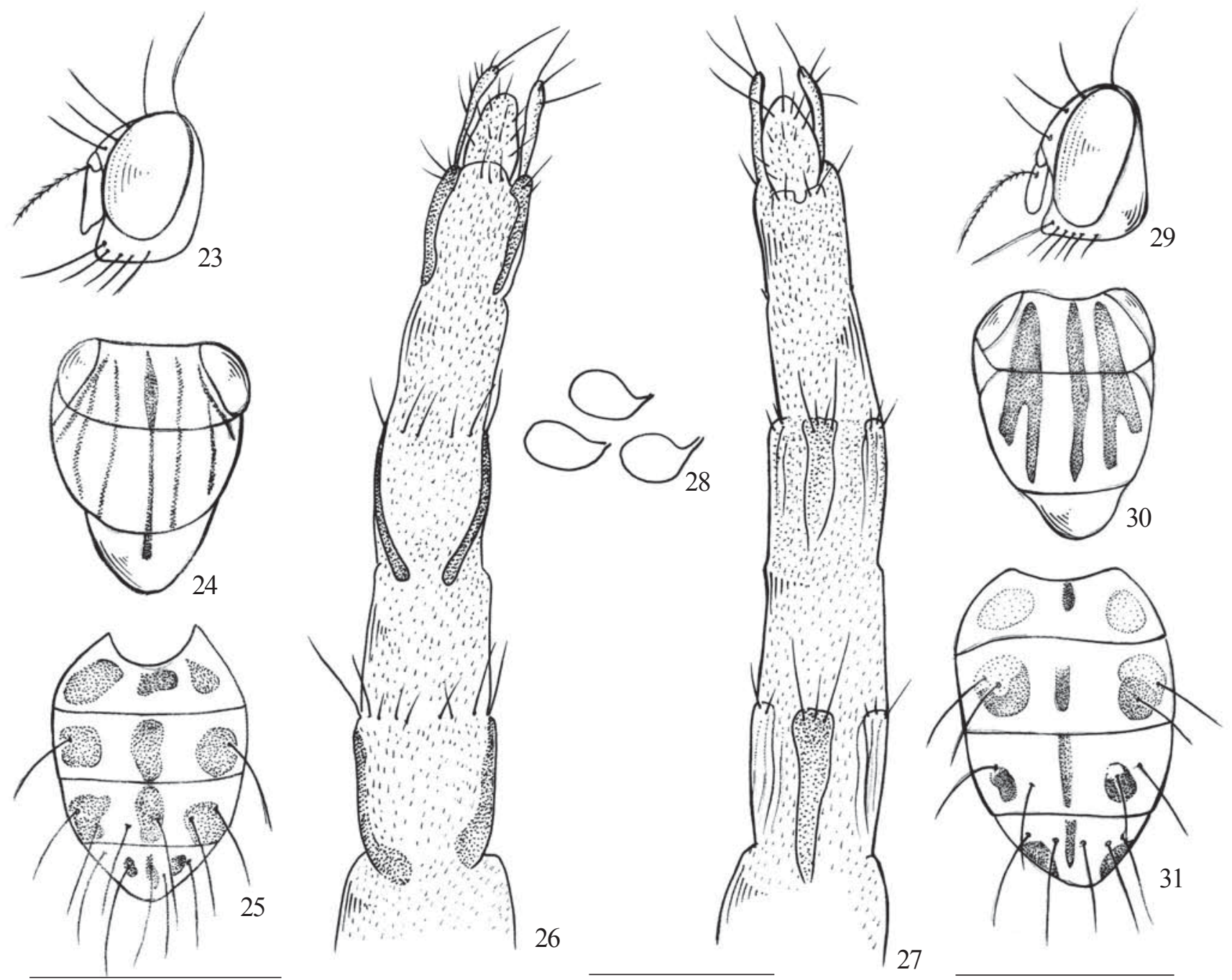

Figs. 23-31. 23-28, Neodexiopsis legitima sp. nov., female: 23, Head, lateral view; 24, Mesonotum, dorsal view; 25, Abdomen, dorsal view; 26, Ovipositor, dorsal view; 27, Ovipositor, ventral view; 28 , Spermathecae. Scale bar, figs. $23-25=2 \mathrm{~mm}$; figs. $26-28=0,5 \mathrm{~mm}$. $29-31$, Neodexiopsis paranaensis sp. nov., male: 29, Head, lateral view; 30, Mesonotum, dorsal view; 31, Abdomen, dorsal view. Scale bar $=2 \mathrm{~mm}$.

ibidem, 11.VIII.1986, 1 male and 9 females; ibidem, 25.VIII.1986, 1 female; ibidem, 01.IX.1986, 1 male; ibidem, 08.IX.1986, 2 females; ibidem, 15.IX.1986, 2 males and 2 females; ibidem, 29.IX.1986, 2 females; ibidem, 06.X.1986, 2 males and 5 females; ibidem, 13.X.1986, 1 male and 2 females; ibidem, 20.X.1986, 4 females; ibidem, 27.X.1986, 2 females; ibidem, 03.XI.1986, 2 females; ibidem, 10.XI.1986, 3 females; ibidem, 17.XI.1986, 1 female; ibidem, 24.XI.1986, 1 female; ibidem, 01.XII.1986, 1 female; ibidem, 22.XII.1986, 1 male; ibidem, 12.I.1987, 1 female; ibidem, 26.I.1987, 1 female; ibidem, 02.II.1987, 1 female; ibidem, 09.III.1987, 1 female; ibidem, 20.VII.1987, 2 females; ibidem, 27.VII.1987, 3 females. Guarapuava, Estância Águas Sta. Clara, 04.VIII.1986, 3 females, Lev. Ent. PROFAUPAR, Malaise; ibidem, 11.VIII.1986, 9 females; ibidem, 18.VIII.1986, 1 female; ibidem, 25.VIII.1986, 5 males and 4 females; ibidem, 01.IX.1986, 12 males and 7 females; ibidem, 15.IX.1986, 3 females; ibidem, 06.X.1986, 2 females; ibidem, 03.XI.1986, 2 females.

\section{Neodexiopsis legitima sp. nov.}

(Figs. 23-28)

Diagnosis.-Antenna dark brown. Ocellar seta long. Height of gena $0.12-0.14$ of eye height (Fig. 23). Mesonotum brown with grey pollinosity and with 5 fine and well marked brown vittae at acrostichal, dorsocentral and intra-alar surfaces (Fig. 24). Scutellar apical seta as long as the basal one. Legs brown, base of all femora and femora-tibial articulations reddish yellow. Hind tibia with a short median anteroventral seta.

Female.-Length: body: 3.1-4.7 mm; wing: 3.2-4.7 mm.

Colour: general colour brown with grey pollinosity. Parafacial, fronto-orbital plates and area around ocellar triangle grey polinose. Face and frons brown. Antenna, arista and palpus dark brown; pedicel yellow at extreme apex. Calypter whitish and halter yellow. Wing hyaline. Mesonotum brown with grey pollinosity and with 5 fine and well marked brown vittae at acrostichal, dorsocentral and intra-alar surfaces (Fig. 24). Pleurae brown with grey pollinosity. Legs brown, base of all femora and femora-tibial articulations reddish yellow. Abdomen brown with grey pollinosity; brown lateral marks and a median vitta in all tergites. (Fig. 25). 


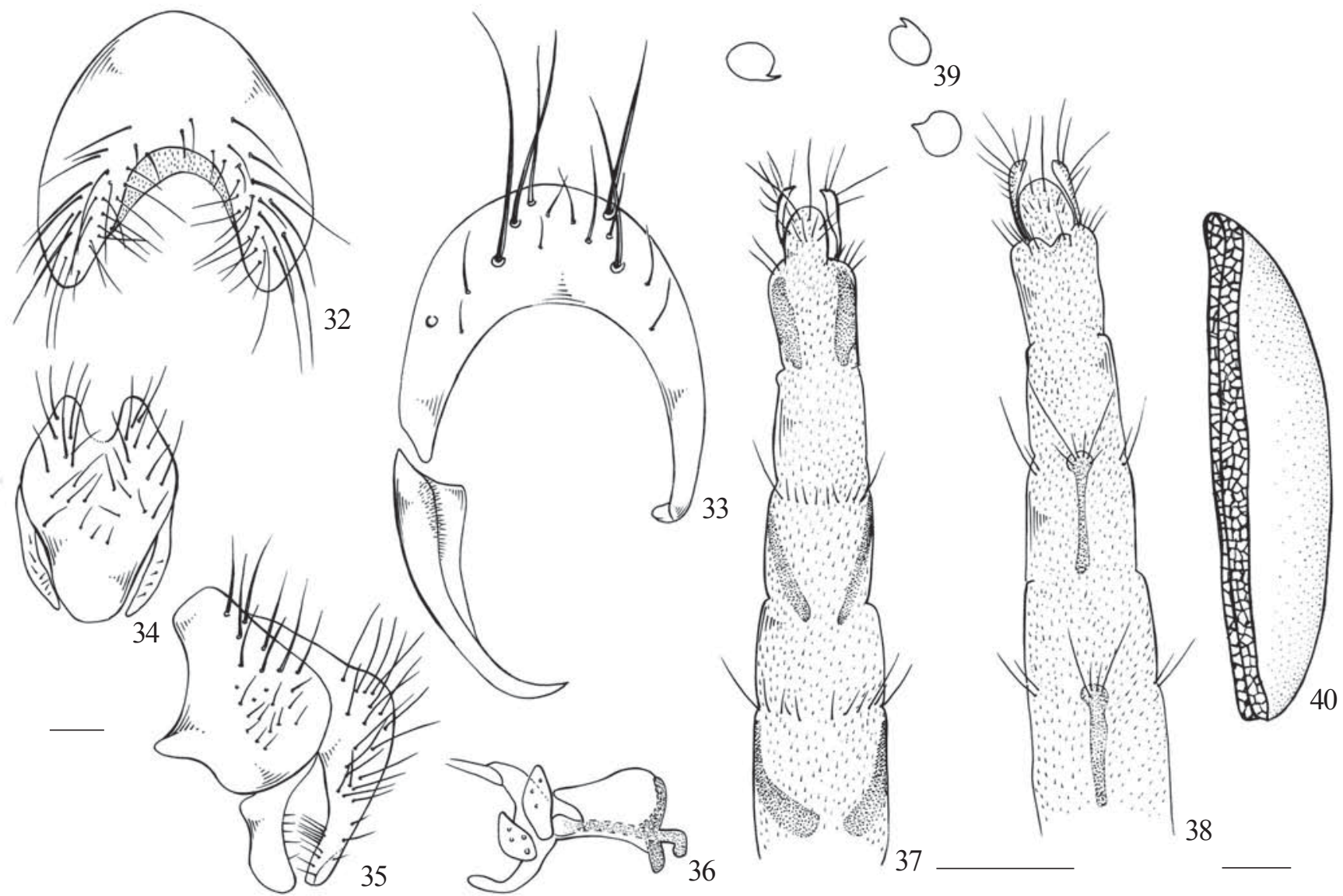

Figs. 32-40. 32-36, Neodexiopsis paranaensis sp. nov., male: 32, Sternite 5, dorsal view; 33, Sternite 6, dorsal view; 34, Cercal plate and surstyli, dorsal view; 35, Cercal plate and surstyli, lateral view; 36, Phallic complex, lateral view. Scale bar $=0,1 \mathrm{~mm}$. 37-40, Neodexiopsis paranaensis sp. nov., female: 37, Ovipositor, dorsal view; 38, Ovipositor, ventral view; 39, Spermathecae; 40, Ova. Scale bar, figs. 37-39=0,5 mm; fig. 40 $=0,1 \mathrm{~mm}$

Head: eyes bare; at level of anterior ocellus separated by 0.41 of head width. Inner and outer vertical setae medium, the latter one outwards directed. Frontal row with 3 pairs of long setae, the upper one backwards directed. Ocellar setae long and forwards directed. Antenna with flagellum long, about 44.2 times as long as pedicel. Arista shortly pubescent. Height of the gena about $0.12-0.14$ of eye height (Fig. 23).

Thorax: acrostichal hairs distinct, in 2 rows, the last pair longer. Presuturals 1; supra-alar 1; post supra-alar 1. Scutellum with two long pairs of setae, a basal and an apical one. Anepimeron with 4 long setae. Fore femur with complete rows of anterodorsal, anterior and anteroventral setae. Tibia on posterior surface with a long median seta; one dorsal seta on apical third, one pre-apical posterodorsal and one ventral apical. Mid femur on with 2-3 anterior setae inserted on middle third; ventral surface with sparse setae; posterior surface with 2 preapical setae. Mid tibia with a sub-median anterior seta and a posterior median seta; ventral, anteroventral and posteroventral apical strong setae. Hind femur with complete rows of anterodorsal and anteroventral setae; ventral surface with fine and long bristles on basal half. Hind tibia with an anterodorsal and a posterodorsal median setae, one short submedian anteroventral and one dorsal pre-apical; anterodorsal, anteroventral and ventral surfaces with an apical seta.

Abdomen: tergite 3 with lateral setae; tergites 4 and 5 with a row of discal setae (Fig. 25).

Ovipositor: Figs. 26, 27. Spermatheca: Fig. 28.

Geographical distribution: Brazil (Paraná).

Comments. Male unknown.

Holotype female. BRAZIL: Paraná, Guarapuava, Est. [resort] Águas Sta. Clara, 01.IX.1986, Lev. [survey] Ent. [entomological] PROFAUPAR [entomological project of Paraná State], Malaise [trap] (DZUP).

Paratypes.-176 females (DZUP, MNRJ): BRAZIL: Paraná, Colombo, Embrapa, BR. 475, Km. 20, 04.VIII.1986 (2), Lev. Ent. PROFAUPAR, Malaise; ibidem, 11.VIII.1986 (1); ibidem, 25.VIII.1986 (1); ibidem, 06.X.1986 (3); ibidem, 13.X.1986 (2); ibidem, 20.X.1986 (5); ibidem, 01.IX.1986 (2); ibidem, 08.X.1986 (3); ibidem, 15.X.1986 (2); ibidem, 03.XI.1986 (3); ibidem, 10.XI.1986 (2); ibidem, 17.XI.1986 (4); ibidem, 24.XI.1986 (2); ibidem, 15.XII.1986 (1); ibidem, 22.XII.1986 (2); ibidem, 29.XII.1986 (1); ibidem, 05.I.1987 (1); ibidem, 19.I.1987 (1); ibidem, 09.II.1987 (1). Ponta Grossa, Vila Velha, reserva IAPAR, BR. 376, 04.VIII.1986 (1), Lev. Ent. PROFAUPAR, Malaise; ibidem, 11.VIII.1986 (2); ibidem, 25.VIII.1986 

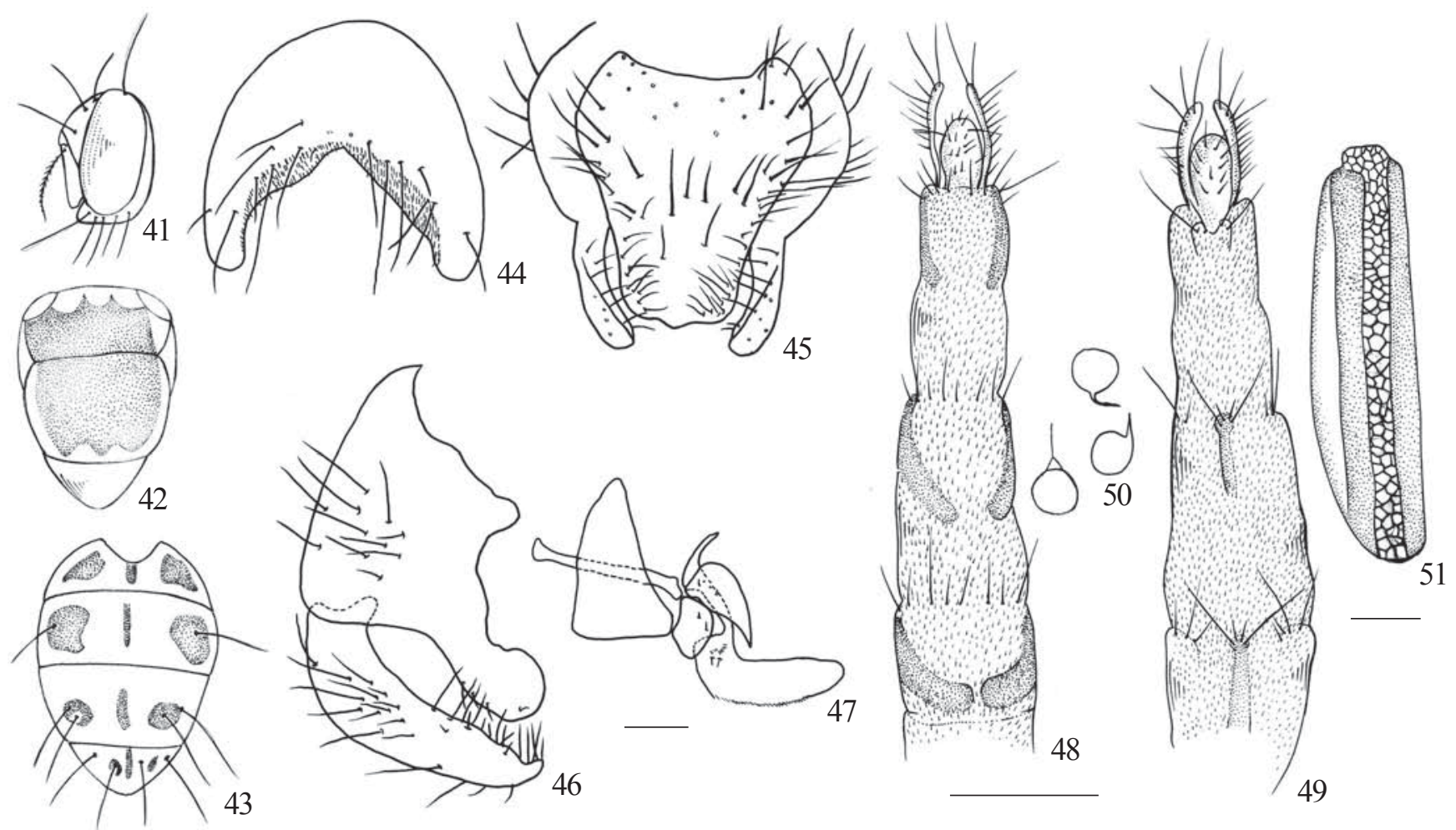

Figs. 41-51. 41-47, Neodexiopsis pura sp. nov., male: 41, Head, lateral view; 42, Mesonotum, dorsal view; 43, Abdomen, dorsal view; 44, Sternite 5, dorsal view; 45, Cercal plate and surstyli, dorsal view; 46, Cercal plate and surstyli, lateral view; 47, Phallic complex, lateral view. Scale bar, figs. 41-43 = $2 \mathrm{~mm}$; figs. 44-47 = 0,1 mm. 48-51, Neodexiopsis pura sp. nov., female: 48, Ovipositor, dorsal view; 49, Ovipositor, ventral view; 50, Spermathecae; 51 , Ova. Scale bar, figs. $48-50=0,5 \mathrm{~mm}$; fig. $51=0,1 \mathrm{~mm}$.

(2); ibidem, 01.IX.1986 (1); ibidem, 08.IX.1986 (6); ibidem, (15). IX.1986 (1); ibidem, 22.IX.1986 (2); ibidem, 06.X.1986 (2); ibidem, 13.X.1986 (3); ibidem, 20.X.1986 (3); ibidem, 27.X.1986 (2); ibidem, 03.XI.1986 (3); ibidem, 10.XI.1986 (5); ibidem, 17.XI.1986 (1); ibidem, 24.XI.1986 (3); ibidem, 01.XII.1986 (2); ibidem, 08.XI.1986 (5); ibidem, 15.XII.1986 (3); ibidem, 22.XII.1986 (1); ibidem, 29.XII.1986 (4); ibidem, 05.I.1987 (2); ibidem, 12.I.1987 (7); ibidem, 19.I.1987 (3); ibidem, 26.I.1987 (4); ibidem, 02.II.1987 (5); ibidem, 09.II.1987 (4); ibidem, 23.II.1987 (1); ibidem, 09.III.1987 (1); ibidem, 06.IV.1987 (1); ibidem, 13.IV.1987 (2); ibidem, 08.VI.1987 (1); ibidem, 06.VII.1987 (2); ibidem, 13.VII.1987 (1); ibidem, 20.VII.1987 (1). Guarapuava, Est. Águas Sta. Clara, 04.VIII.1986 (4), Lev. Ent. PROFAUPAR, Malaise; ibidem, 11.VIII.1986 (4); ibidem, 18.VIII.1986 (2); ibidem, 25.VIII.1986 (1); ibidem, 01.IX.1986 (1); ibidem, 08.IX.1986 (3); ibidem, 15.IX.1986 (2); ibidem, 22.IX.1986 (4); ibidem, 29.IX.1986 (3); ibidem, 06.X.1986 (3); ibidem, 13.X.1986 (3) ; ibidem, 20.X.1986 (3); ibidem, 27.X.1986 (3); ibidem, 03.XI.1986 (5); ibidem, 8.XI.1986 (1); ibidem, 17.XI.1986 (1); ibidem, 24.XI.1986 (1); ibidem, 15.XII.1986 (2); ibidem, 22.XII.1986 (1); ibidem, 29.XII.1986 (1); ibidem, 05.I.1987 (1); ibidem, 26.I.1987 (1); ibidem, 13.IV.1987 (1) ; ibidem, 15.VI.1987 (1).

\section{Neodexiopsis paranaensis $\mathbf{s p . ~ n o v . ~}$}

(Figs. 29-40)

Diagnosis.-Antenna dark brown, apex of pedicel lighter. Ocellar seta long. Height of gena 0.10 of eye height (Fig. 29). Mesonotum brown with grey pollinosity and with 5 brown vittae at acrostichal, dorsocentral and intra-alar surfaces (Fig.
30). Scutellar apical seta as long as the basal one. Legs brown, with mid and hind femur yellow at basal half. Hind tibia with no short median anteroventral seta.

Male.-Length: body: $4.1-4.7 \mathrm{~mm}$; wing: $5-5.5 \mathrm{~mm}$.

Colour: parafacial, fronto-orbital plates, face and frons brown, grey pollinose. Antenna dark brown, with apex of pedicel lighter. Arista and palpus dark brown. Calypter whitish and halter yellow. Wing hyaline. Mesonotum brown with grey pollinosity and with 5 brown vittae at acrostichal, dorsocentral and intra-alar surfaces (Fig. 30). Pleurae brown with grey pollinosity. Legs brown, with mid and hind femur yellow at basal half. Abdomen brown with grey pollinosity; tergites $1+2$ -3 , yellow laterally; tergites 3 and 5 with a median brown stripe and two brown lateral clouds (Fig. 31).

Head: eyes bare; at level of anterior ocellus separated by $0.33-0.34$ of head width. Inner and outer vertical setae medium, the latter one outwards directed. Frontal row with 3 pairs of long setae, the upper one backwards directed. Ocellar setae long and forwards directed. Antenna with flagellum 3.0-3.2 times as long as pedicel. Arista shortly pubescent. Height of the gena about 0.10 of eye height (Fig. 29).

Thorax: acrostichal hairs distinct, in 2 rows, the last pair longer. Presuturals 1; supra-alar 1; post supra-alar 1. Scutellum with two long pairs of setae, a basal and an apical one. Anepimeron with 3 long setae. Fore femur with complete rows 

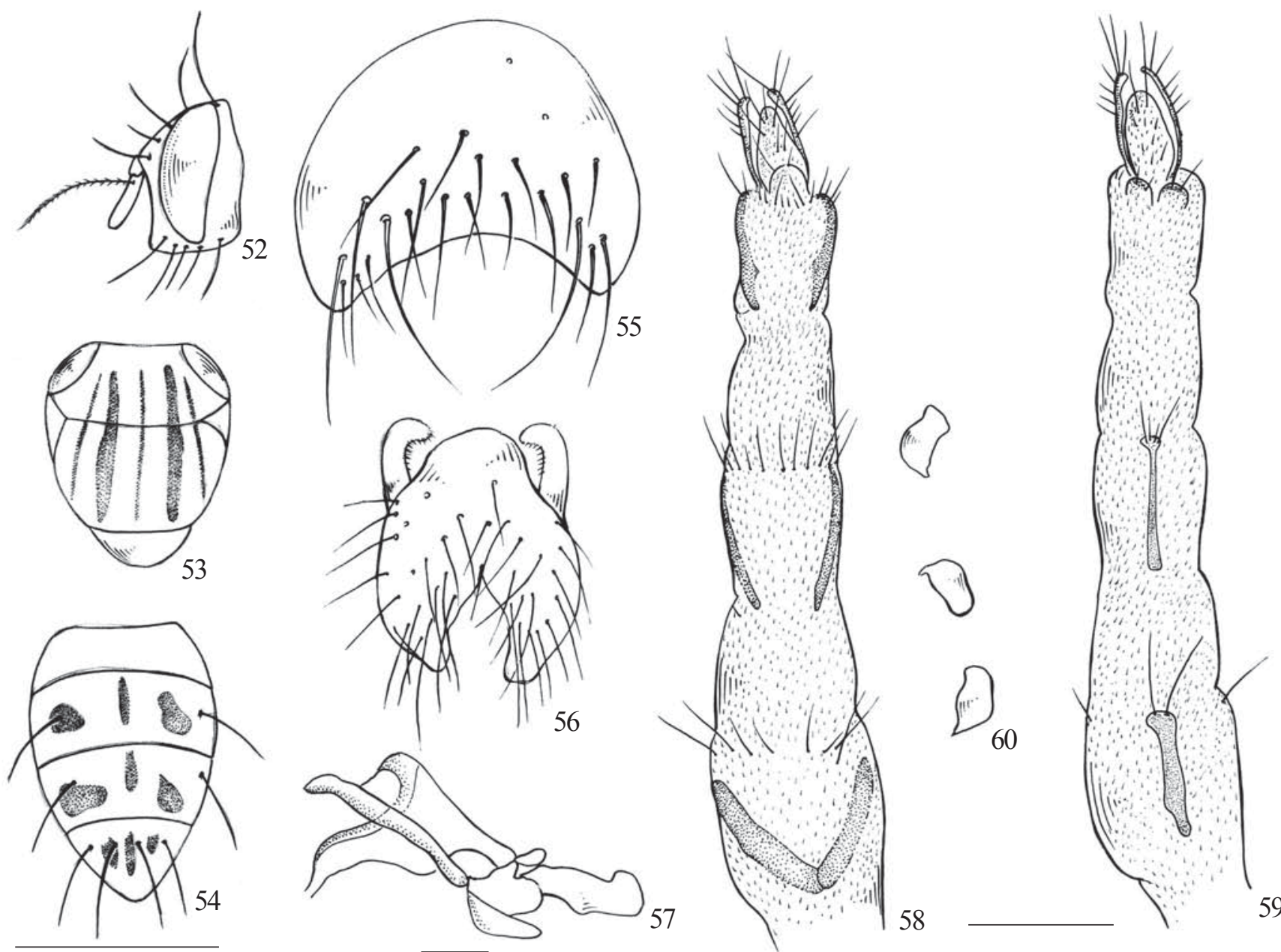

Figs. 52-60. 52-57, Neodexiopsis rara sp. nov., male: 52, Head, lateral view; 53, Mesonotum, dorsal view; 54, Abdomen, dorsal view; 55, Sternite 5, dorsal view; 56, Cercal plate and surstyli, dorsal view; 57, Phallic complex, lateral view. Scale bar, figs. 52-54=2 mm; figs. 55-57=0,1 mm. 58-60, Neodexiopsis rara sp. nov., female: 58, Ovipositor, dorsal view; 59, Ovipositor, ventral view; 60 , Spermathecae. Scale bar $=0,5 \mathrm{~mm}$.

of anterodorsal and anteroventral setae. Tibia on posterior surface with a long median seta; dorsal, posterodorsal and posterior surfaces with an apical seta. Mid femur with anterior setae inserted on basal half; posterior surface with 2 pre-apical setae. Mid tibia with a sub-median anterior seta and a posterior median seta; ventral, anteroventral and posteroventral apical strong setae. Hind femur with complete rows of anterodorsal and anteroventral setae, the last sparse; posterior surface with a pre-apical seta. Hind tibia with an anterodorsal and a posterodorsal median seta and one dorsal pre-apical; anterodorsal, anteroventral and ventral surfaces with an apical seta.

Abdomen: tergites 3-4 with 2 lateral setae, tergite 5 with a row of discal setae (Fig. 31).

Terminalia. Sternite 5 (Fig. 32). Sternite 6 asymmetric (Fig. 33). Cercal plate (Figs. 34, 35). Aedeagus (Fig. 36).

Female. Similar to male, except for the yellow marks at abdomen, which are very faint and not visible in some female specimens. 40.

Ovipositor: Figs. 37-38. Spermatheca: Fig. 39. Ova: Fig.

Geographical distribution: Brazil (Paraná).

Comments. This species can be identified by chaetotaxy of mid and hind legs.

Holotype male. BRAZIL: Paraná, Ponta Grossa, Vila Velha, reserva IAPAR, BR. 376 [road], 11.VIII.1986, Lev. [survey] Ent. [entomological] PROFAUPAR [entomological project of Paraná State], Malaise [trap] (DZUP).

Paratypes.-38 males and 103 females (DZUP, MNRJ): BRAZIL: Paraná, Colombo, Embrapa, BR. 475, Km. 20, 18.VIII.1986, 1 female, Lev. Ent. PROFAUPAR. Malaise; ibidem, 01.IX.1986, 2 females; ibidem, 22.IX.1986, 1 female; ibidem, 13.X.1986, 2 males; ibidem, 20.X.1986, 3 females; ibidem, 03.XI.1986, 2 females and 4 males; ibidem, 10.XI.1986, 2 females; ibidem, 17.XI.1986, 1 female; ibidem, 24.XI.1986, 2 females; ibidem, 05.I.1987, 3 females; ibidem, 26.I.1987, 3 females; ibidem, 02.II.1987, 1 female. Ponta Grossa, Vila Velha, reserva IAPAR, BR. 376, 04.VIII.1986, 1 female, Lev. Ent. PROFAUPAR, Malaise; ibidem, 11.VIII.1986, 9 females; ibidem, 25.VIII.1986, 1 female; ibidem, 01.IX.1986, 2 males; ibidem, 08.IX.1986, 1 female; ibidem, 15.IX.1986, 1 male and 8 females; ibidem, 22.IX.1986, 2 females; ibidem, 29.IX.1986, 1 male and 1 


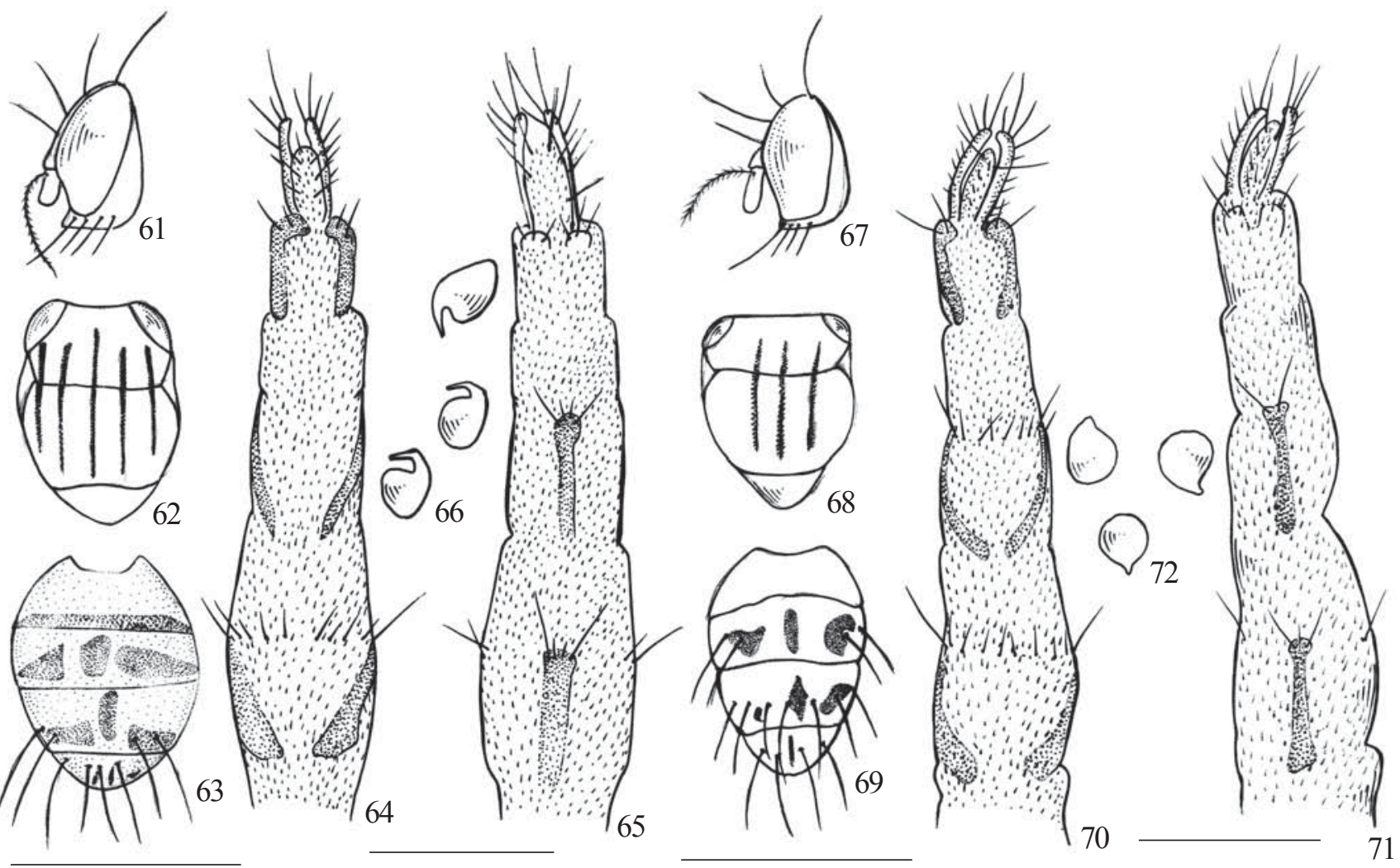

Figs. 61-72. 61-66, Neodexiopsis similis sp. nov., female: 61, Head, lateral view; 62, Mesonotum, dorsal view; 63, Abdomen, dorsal view; 64, Ovipositor, dorsal view; 65, Ovipositor, ventral view; 66, Spermathecae. Scale bar, figs. 61-63 = $2 \mathrm{~mm}$; figs. $64-66=0,5 \mathrm{~mm} .67-72$, Neodexiopsis uber sp. nov., female: 67, Head, lateral view; 68, Mesonotum, dorsal view; 69, Abdomen, dorsal view; 70, Ovipositor, dorsal view; 71, Ovipositor, ventral view; 72, Spermathecae. Scale bar, figs. $67-69=2 \mathrm{~mm}$; figs. $70-72=0,5 \mathrm{~mm}$.

female; ibidem, 06.X.1986, 5 males and 2 females; ibidem, 13.X.1986, 5 males and 3 females; ibidem, 20.X.1986, 10 males and 6 females; ibidem, 27.X.1986, 3 males and 2 females; ibidem, 03.XI.1986, 3 males and 7 females; ibidem, 10.XI.1986, 1 male and 4 females; ibidem, 17.XI.1986, 1 female; ibidem, 24.XI.1986, 1 female; ibidem, 02.II.1987, 1 male; ibidem, 09.II.1987, 1 female; ibidem, 20.VII.1987, 1 female. Guarapuava, Est. Aguas Sta. Clara, 11.VIII.1986, 7 females, Lev. Ent. PROFAUPAR, Malaise; ibidem, 18.VIII.1986, 2 females; ibidem, 25.VIII.1986, 6 females; ibidem, 01.IX.1986, 3 females; ibidem, 08.IX.1986 5 females; ibidem, 15.IX.1986, 3 females; ibidem, 06.X.1986, 1 female; ibidem, 20.X.1986, 1 female; ibidem, 10.XI.1986, 1 female; ibidem, 12.I.1987, 1 female; ibidem, 09.III.1987, 1 female.

\section{Neodexiopsis pura sp. nov.}

(Figs. 41-51)

Diagnosis.-Antenna dark brown with apex of pedicel yellow; flagellum very long, about 4.0-4.2 of the pedicel. Ocellar seta long. Height of gena about 0.11 of eye height (Fig. 41). Mesonotum brown with grey pollinosity, with no marks of vittae (Fig. 42); in some specimens 3 very faint brown vittae at acrostichal and dorsocentral surfaces. Scutellar apical seta as long as the basal one. Male with legs yellow, brown on dorsal half of fore femur and on apical third of mid and hind femora; tarsi brown. Female with fore femur and tibia brown, yellow at apex; mid femur yellow on basal fourth, mid tibia brown; hind femur almost enterily yellow, except at apical half of dorsal surface; hind tibia brown yellowish to apex. Hind tibia with a short median anteroventral seta.

Male.-Length: body: 3.1-3.4 mm; wing: 3.3-3.7 mm.

Colour: parafacial, fronto-orbital plates and area around ocellar triangle golden polinose. Face and frons brown. Antenna dark brown. Arista and palpus dark brown. Calypter whitish and halter yellow. Wing hyaline. Mesonotum brown with grey pollinosity, with no marks of vittae (Fig. 42); in some specimens 3 very faint brown vittae at acrostichal and dorsocentral surfaces. Scutellar apical seta as long as the basal one. Male with legs yellow, brown on dorsal half of fore femur and on apical third of mid and hind femora; tarsi brown. Female with fore femur and tibia brown, yellow at apex; mid femur yellow on basal fourth, mid tibia brown; hind femur almost all yellow, except at apical half of dorsal surface; hind tibia brown yellowish to apex. Abdomen brown with grey pollinosity; all tergites with brown lateral marks and one long median stripe (Fig. 43).

Head: eyes bare; at level of anterior ocellus separated by 0.36 of head width. Inner and outer vertical setae medium, the latter one outwards directed. Frontal row with 3 pairs of long setae, the upper one backwards directed. Ocellar setae long and forwards directed. Antenna with flagellum 4.0-4.2 times 
as long as pedicel, vibrissa long. Arista shortly pubescent. Height of the gena about 0.11 of eye height (Fig. 41).

Thorax: acrostichal hairs distinct, in 2 rows, the last pair longer. Presuturals 1; supra-alar 1; post supra-alar 1. Scutellum with two long pairs of setae, a basal and an apical one. Anepimeron with 4 long setae. Fore femur with complete rows of anterodorsal and anteroventral setae. Tibia on posterior surface with a long median seta; a pre-apical posterior seta. Mid femur with anterior setae on basal half; ventral surface with 3-5 sparse setae; posterior surface with 2 pre-apical setae. Mid tibia with a sub-median anterior seta and a posterior median seta; anterior, ventral, posterior and dorsal apical setae. Hind femur with complete rows of anterodorsal and anteroventral setae; ventral surface with fine and long setae on basal half. Hind tibia with a long anterodorsal and a long posterodorsal setae, one sub-median anteroventral short, one dorsal on apical third and a long ventral apical.

Abdomen: tergites 3 with a pair of lateral setae; tergite 4 with 2 pairs of lateral setae and tergite with a row of discal setae (Fig. 43). Sternite 5 (Fig. 44).

Terminalia: Cercal plate (Figs. 45-46). Aedeagus (Fig. 47).

Female. Similar to male, except for legs colour, above described. $51)$.

Ovipositor: (Figs. 48-49). Spermatheca (Fig. 50). Ova (Fig.

Geographical distribution: Brazil (Paraná).

Comments. This species can be identified by characters used in the key.

Holotype male. BRAZIL: Paraná, Colombo, Embrapa, BR. 475 [road], Km. 20, 22.IX.1986, Lev. [survey] Ent. [entomological] PROFAUPAR [entomological project of Paraná State], Malaise [trap] (DZUP).

Paratypes. -5 males and 10 females (DZUP, MNRJ): BRAZIL: Paraná, Colombo, Embrapa, BR. 475, Km 20, 15.IX.1986, 1 female, Lev. Ent. PROFAUPAR, Malaise; ibidem 20.X.1986, 1 female; ibidem, 27.X.1986, 1 female; ibidem, 17.XI.1986, 1 female; ibidem, 19.I.1987, 1 male. Guarapuava, Est. Águas Sta. Clara, 04.VIII.1986, 1 male, Lev. Ent. PROFAUPAR, Malaise; ibidem, 11.X.1986, 1 female; ibidem, 01.IX.1986, 1 female; ibidem, 08.IX.1986, 1 female; ibidem, 13.X.1986, 1 male; ibidem, 20.X.1986, 2 females; ibidem, 27.X.1986, 1 male and 1 female; ibidem, 30.III.1987, 1 male.

\section{Neodexiopsis rara sp. nov.}

(Figs. 52-60)

Diagnosis.-Antenna dark brown, with apex of pedicel lighter. Ocellar seta short. Height of gena $0.05-0.075$ of eye height (Fig. 52). Mesonotum brown with golden pollinosity and with 5 brown vittae at acrostichal, dorsocentral and intraalar surfaces (Fig. 53). Scutellar apical seta as long as the basal one. Legs yellow, fore leg brownish. Hind tibia with a short median anteroventral seta.

Male.-Length: body: 4,1-4,7 mm; wing: 4,5-5,2 mm.

Colour: parafacial, fronto-orbital plate, face and frons brown with grey pollinosity. Antenna dark brown, with apex of pedicel lighter. Arista and palpus dark brown. Calypter whitish and haltere yellow. Wing hyaline. Mesonotum brown with grey pollinosity and with 5 brown vittae at acrostichal, dorsocentral and intra-alar surfaces (Fig. 53). Pleurae brown with grey pollinosity. Legs yellow, fore leg brownish. Abdomen brown with grey pollinosity; tergites $3-5$, with brown lateral clouds and one long median stripe (Fig. 54).

Head: eyes bare; at level of anterior ocellus separated by 0.33 of head width. Inner and outer vertical setae medium, the latter one outwards directed. Frontal row with 3 pairs of long setae, the upper one backwards directed. Ocellar setae short and forwards directed. Antenna with flagellum 3.2 times as long as pedicel. Arista shortly pubescent. Height of the gena about $0.05-0.75$ of eye height (Fig. 52).

Thorax: acrostichal hairs distinct, in one irregular row, the last pair longer. Presuturals 1; supra-alar 1; post supra-alar 1 . Scutellum with two long pairs of setae, a basal and an apical one. Anepimeron with 4 long setae. Fore femur with complete rows of anterodorsal and anteroventral setae. Tibia on posterior surface with a long median seta; dorsal, posterodorsal and posterior surfaces with an apical seta. Mid femur on with anterior setae on basal half, the median long; posterior surface with 2 pre-apical setae. Mid tibia with a sub-median anterior seta and a posterior median one; ventral, anteroventral and posteroventral apical strong setae. Hind femur with complete rows of anterodorsal and anteroventral setae; ventral surface with fine and long setae on basal half. Hind tibia with an anterodorsal and a posterodorsal median setae, one short and fine sub-median anteroventral, one dorsal pre-apical; anterodorsal, anteroventral and ventral surfaces with an apical seta.

Abdomen: tergites 3-4 with one pair of lateral setae, tergite 5 with 4 setae at disc (Fig. 54). Sternite 5 (Fig. 55).

Terminalia: Cercal plate (Fig. 56). Aedeagus (Fig. 57).

Female. Similar to male.

Ovipositor: (Figs. 58-59). Spermatheca (Fig. 60).

Geographical distribution: Brazil (Paraná).

Comments. This species can be identified by characters used in the key.

Holotype male. BRAZIL: Paraná, Colombo, Embrapa, BR. 475 [road], Km. 20, 11.VIII.1986, Lev. [survey] Ent. [entomological] PROFAUPAR [entomological project of Paraná State], Malaise [trap] (DZUP).

Paratypes. -7 males and 1 female (DZUP, MNRJ): BRAZIL: Paraná, Colombo, Embrapa, BR. 475, Km. 20, 04.VII.1986, 1 male, Lev. Ent. PROFAUPAR, Malaise; ibidem, 11.VIII1986, 1 male; ibidem, 20.X.1986, 1 female; ibidem, 29.XII.1986, 2 males; ibidem, 12.I.1987, 2 males; ibidem, 19.I.1987, 1 male; ibidem, 23.II.1987, 1 male.

\section{Neodexiopsis similis $\mathbf{s p . ~ n o v . ~}$}

(Figs. 61-66)

Diagnosis.-Antenna brown, apex of pedicel yellow and basal third of flagellum yellow; flagellum about 3.2 of the pedicel. Ocellar seta short. Height of gena 0.12 of eye height (Fig. 61). Mesonotum brown with grey pollinosity and with 5 brown vittae at acrostichal, dorsocentral and intra-alar surfaces (Fig. 62). Scutellar basal seta long and apical seta short. Legs yellow with apical $1 / 4$ of hind femur brown, tarsi brown. Abdomen with tergites greyish yellow, with brown lateral and median marks (Fig. 63). 
Female.-Length: body: 3.2-3.6 mm; wing: 3.6-4,0 mm

Colour: parafacial, fronto-orbital plates, face and frons brown with grey pollinosity. Antenna brown, apex of pedicel yellow and basal third of flagellum yellow. Arista and palpus dark brown. Calypter whitish and halter yellow. Wing hyaline. Mesonotum brown with grey pollinosity and with 5 brown vittae at acrostichal, dorsocentral and intra-alar surfaces (Fig. 62). Pleurae brown with grey pollinosity. Legs yellow with apical $1 / 4$ of hind femur brown, tarsi brown. Abdomen with tergites greyish yellow, with brown lateral and median marks (Fig. 63)

Head: eyes bare; at level of anterior ocellus separated by 0.33 of head width. Inner and outer vertical setae medium, the latter one outwards directed. Frontal row with 3 pairs of long setae, the upper one backwards directed; ocellar seta short. Antenna with flagellum about 3.2 of the pedicel. Arista shortly pubescent. Height of gena 0.12 of eye height (Fig. 61).

Thorax: acrostichal hairs distinct, in 1 row, the last pair longer. Presuturals 1; supra-alar 1; post supra-alar 1. Scutellum with long basal and a short apical pair of setae. Anepimeron with 4 long setae. Fore femur with complete rows of anterodorsal and anteroventral setae. Tibia on posterior surface with a long median seta; dorsal, posterodorsal and posterior surfaces with an apical seta. Mid femur on with 2-3 anterior setae inserted on middle third; posterior surface with 2 pre-apical setae. Mid tibia with a sub-median anterior seta and a posterior median seta; ventral, anteroventral and posteroventral apical strong setae. Hind femur with complete rows of anterodorsal and anteroventral setae; ventral surface with fine and long setae on basal half. Hind tibia with an anterodorsal and a posterodorsal median seta; one dorsal preapical; anterodorsal, anteroventral and ventral surfaces with an apical seta.

Abdomen: tergite 4 with lateral setae, tergite 5 with a discal row of setae (Fig. 63).

Ovipositor: (Figs. 64-65). Spermatheca (Fig. 66).

Geographical distribution: Brazil (Paraná).

Comments. Male unknown.

Holotype female. BRAZIL: Paraná, Guarapuava, Est. [resort] Águas Sta. Clara, 03.XI.1986, Lev. [survey] Ent. [entomological] PROFAUPAR [entomological project of Paraná State], Malaise [trap] (DZUP).

Paratypes.-33 females (DZUP, MNRJ): BRAZIL: Paraná, Colombo, Embrapa, BR. 475, Km 20.17.XI.1986, (4), Lev. Ent. PROFAUPAR, Malaise. Ponta grossa (Vila Velha), Reserva IAPAR, BR 376, 06.X.1986, (2), Lev. Ent. PROFAUPAR, Malaise; ibidem, 27.X.1986, (2); ibidem, 08.XII.1986, (1); ibidem, 02.II.1987, (1); ibidem, 09.II.1987, (1); ibidem, 02.III.1987, (1). Guarapuava, Est. Águas Sta. Clara, 04.VIII.1986, (5), Lev. Ent. PROFAUPAR, Malaise; ibidem 11.VIII.1986, (2); ibidem, 18.VIII.1986, (1); ibidem, 25.VIII.1986, (4); ibidem, 01.IX.1986, (3); ibidem, 22.IX.1986, (1); ibidem, 13. X.1986, (1); ibidem, 03.XI.1986, (2); ibidem, 15.XII.1986, (2).

\section{Neodexiopsis uber sp. nov.}

(Figs. 67-72)

Diagnosis.-Antenna dark brown, with apex of pedicel and basal third of flagellum yellow. Ocellar seta long. Height of gena 0.10 of eye height (Fig. 67). Mesonotum brown with grey pollinosity and with 3 fine brown vittae at acrostichal and dorsocentral surfaces (Fig. 68). Scutellar apical seta as long as the basal one. Legs yellow with dorsal surface of fore femur and apical fourths of mid and hind femora brown. Hind tibia with a short median anteroventral seta.

Female.-Length: body: 3.0-3.9 mm; wing: 3.1-4.4 mm

Colour: parafacial, fronto-orbital plates, face and frons brown, grey pollinose. Antenna brown, with apex of pedicel yellow. Arista brown. Palpus yellow. Calypter whitish and haltere yellow. Wing hyaline. Mesonotum brown with golden pollinosity and with 3 fine brown vittae at acrostichal and dorsocentral surfaces (Fig. 68). Pleurae brown with grey pollinosity. Legs yellow with dorsal surface of fore femur and apical fourths of mid and hind femora brown. Abdomen brown with grey pollinosity; tergites 3-4, with brown lateral clouds and one median stripe; tergite 5 with a median brown stripe (Fig. 69).

Head: eyes bare; at level of anterior ocellus separated by $0.30-0.32$ of head width. Inner and outer vertical setae medium, the latter one outwards directed. Frontal row with 3 pairs of long setae, the upper one backwards directed. Ocellar setae long and forwards directed. Antenna with flagellum 2.2-2.4 times as long as pedicel. Arista shortly pubescent. Height of the gena about 0.10 of eye height (Fig. 67).

Thorax: acrostichal hairs distinct, in 2 rows, the last pair longer. Presuturals 1; supra-alar 1; post supra-alar 1. Scutellum with two long pairs of setae, a basal and an apical one. Anepimeron with 4 long setae. Fore femur with complete rows of anterodorsal and anteroventral setae. Tibia on posterior surface with a long median seta; dorsal, posterodorsal and posterior surfaces with an apical seta. Mid femur on with anterior setae on basal half; posterior surface with 2 pre-apical setae. Mid tibia with a sub-median anterior seta and a posterior median seta; ventral, anteroventral and posteroventral apical strong setae. Hind femur with complete rows of anterodorsal and anteroventral setae; ventral surface with fine and long setae on basal half. Hind tibia with an anterodorsal and a posterodorsal seta, one short sub-median anteroventral and one dorsal pre-apical; anterodorsal, anteroventral and ventral surfaces with an apical seta.

Abdomen: tergite 3 with 2 lateral pairs of setae, tergites 4 and 5 with a discal row of setae (Fig. 69).

Ovipositor: (Figs. 70, 71). Spermatheca (Fig. 72).

Geographical distribution: Brazil (Paraná).

Comments. This species can be identified by characters used in the key. Male is unknown.

Holotype female. BRAZIL: Paraná, Guarapuava, Est. [resort] Águas Sta. Clara, 11.VIII.1986, Lev. [survey] Ent. [entomological] PROFAUPAR [entomological project of Paraná State], Malaise [trap] (DZUP).

Paratypes.-337 females (DZUP, MNRJ). BRAZIL: Paraná, Colombo, Embrapa, BR. 475, Km 20.05.0I.1987, 2 females. Lev. Ent. PROFAUPAR. Malaise. Ponta Grossa, Vila Velha, Reserva IAPAR, BR. 376, 04.VIII.1986 (3). Lev. Ent. PROFAUPAR. Malaise; ibidem, 11.VIII.1986 (5); ibidem, 18.VIII.1986 (1); ibidem, 25.VIII.1986 (1); 
ibidem, 15.IX..1986 (6); ibidem, 29.IX.1986 (1); ibidem, 06.X..1986 (7); ibidem, 13.X..1986 (4); ibidem, 20.X.1986 (10); ibidem, 27.X.1986 (1); ibidem, 03.XI.1986 (10); ibidem, 10.XI.1986 (5); ibidem, 17.XI.1986 (3); ibidem, 24.XI.1986 (5); ibidem, $01 . X I I .1986$ (1); ibidem, 08.XII.1986 (8); ibidem, 15.XII.1986 (8); ibidem, 22.XII.1986 (4); ibidem, 29.XII.1986 (4); ibidem, 05.I.1987 (4); ibidem, 12.I.1987 (4); ibidem, 19.I.1987 (6); ibidem, 26.I.1987 (3); ibidem, 02.II.1987 (3); ibidem, 09.II.1987 (5); ibidem, 16.II.1987 (1); ibidem, 23.III.1987 (1); ibidem, 30.III.1987 (1); ibidem, 15.VI.1987 (1); ibidem, 13.VII.1987 (1); ibidem, 20.VII.1987 (2). Guarapuava, Est. Águas Sta. Clara, 04.VIII.1986 (37), Lev. Ent. PROFAUPAR, Malaise; ibidem, 11.VIII.1986 (40); ibidem, 18.VIII.1986 (20); ibidem, 25.VIII.1986 (16); ibidem, 01.IX..1986 (22); ibidem, 08.IX..1986 (12); ibidem, 15.IX..1986 (13); ibidem, 22.IX..1986 (8); ibidem, 29.IX.1986 (4); ibidem, 06.X..1986 (6); ibidem, 13.X..1986 (2); ibidem, 20.X.1986 (2); ibidem, 27.X.1986 (2); ibidem, 03.XI.1986 (4); ibidem, 17.XI.1986 (6); ibidem, 24.XI.1986 (2); ibidem, 08.XII.1986 (1); ibidem, 15.XII.1986 (2); ibidem, 22.XII.1986 (2); ibidem, 29.XII.1986 (2); ibidem, 05.I.1987 (2); ibidem, 12.I.1987 (3); ibidem, 19.I.1987 (3); ibidem, 26.I.1987 (1); ibidem, 02.II.1987 (1); ibidem, 09.II.1987 (1); ibidem, 20.VII.1987 (1); ibidem, 27.VII.1987 (2).

Acknowledgements. Our thanks to the Conselho Nacional de Desenvolvimento Científico e Tecnológico (CNPq) for financial support (300386-80 for MSC and 304148/2002-4 for CJBC). MSC also is grateful to FAPERJ (E-26/170.627/2001) for financial support. To Luciane Marinoni (DZUP) for comments on previous versions of the manuscript. To anonymous referee to improvement the text. To Luis Antonio Alves Costa (MNRJ) for the drawings. This is the contribution number 1489 of the Departamento de Zoologia of the Universidade Federal do Paraná.

\section{REFERENCES}

Carvalho, C. J. B. de. 1989a. Revisão das espécies e posição sistemática de Palpibracus Rondani (Diptera, Muscidae). Revista Brasileira de Zoologia 6: 325-376.
Carvalho, C. J. B. de. 1989b. Classificação de Muscidae (Diptera): uma proposta através da análise cladística. Revista Brasileira de Zoologia 6: 627-648.

Carvalho, C. J. B. de; M. S. Couri; A. C. Pont; D. Pamplona. \& S. M. Lopes. 2005. A catalogue of the Muscidae (Diptera) of the Neotropical region. Zootaxa 860: 1-282.

Costacurta, N. do C.; R. C. Marinoni \& C. J. B. de Carvalho. 2003. Fauna de Muscidae (Diptera) em três localidades do Estado do Paraná, Brasil, capturada por armadilha Malaise. Revista Brasileira de Entomologia 47: 389-397.

Couri, M. S. \& D. de O. Albuquerque. 1979. Estudos sobre Neodexiopsis Malloch, $1920 \mathrm{com}$ notas nomenclaturais sobre Coenosiinae (Diptera, Muscidae). Revista Brasileira de Biologia 39: 499517.

Couri, M. S. \& C. J. B. de Carvalho. 2002. Part II. Apical Groups, p. 133-262. In: Carvalho, C. J. B. de (ed.). Muscidae (Diptera) of the Neotropical Region: taxonomy. Curitiba, Editora Universidade Federal do Paraná, 287 p.

Couri, M. S. \& A. C. Pont. 1999. A key to the world genera of the Coenosiini (Diptera, Muscidae, Coenosiinae). Studia dipterologica 6: $93-102$.

Couri, M. S. \& A. C. Pont. 2000. Cladistic analysis of Coenosiini (Diptera: Muscidae: Coenosiinae). Systematic Entomology 25: 373-392. Malloch, J. R. 1920. Descriptions of New North American Anthomyiidae (Diptera). Transactions of the American Entomological Society 46: 133-196.

McAlpine, J. F. 1981. Morphology and terminology - adults, p. 9-63. In: McAlpine, J. F. et al. (eds.). Manual of Nearctic Diptera, Vol. 1, Monograph 27, Ottawa, Agriculture Canada Research Branch, $674 \mathrm{p}$.

Snyder, F. M. 1957a. Puerto Rican Neodexiopsis (Diptera: Muscidae: Coenosinae). Journal of Agriculture of the University of Puerto Rico 41: 207-229.

Snyder, F. M. 1957b. Notes and Descriptions of some Neotropical Muscidae (Diptera). Bulletin of the American Museum of Natural History 113: 437-490.

Snyder, F. M. 1958. A Review of New World Neodexiopsis (Diptera, Muscidae). The ovata group. American Museum Novitates 1892: $1-27$. 